\title{
Refractive and Biometric Outcomes in Patients with Retinopathy of Prematurity Treated with Intravitreal Injection of Ranibizumab as Compared with Bevacizumab: A Clinical Study of Correction at Three Years of Age
}

\author{
Yen-Chih Chen $\left(\mathbb{D},{ }^{1}\right.$ San-Ni Chen $\left(\mathbb{D},{ }^{1,2,3}\right.$ Benjamin Chi-Lan Yang, ${ }^{4}$ Kun-Hsien Lee, \\ Chih-Chun Chuang $\mathbb{D}^{1}{ }^{1}$ and Chieh-Yin Cheng $\mathbb{D}^{1}$ \\ ${ }^{1}$ Department of Ophthalmology, Changhua Christian Hospital, Changhua, Taiwan \\ ${ }^{2}$ School of Medicine, Chung Shan Medical University, Taichung, Taiwan \\ ${ }^{3}$ Department of Optometry, DaYeh University, Changhua, Taiwan \\ ${ }^{4}$ School of Medicine, National Taiwan University, Taipei, Taiwan \\ Correspondence should be addressed to San-Ni Chen; 108562@cch.org.tw
}

Received 7 November 2017; Accepted 14 January 2018; Published 11 March 2018

Academic Editor: Toshihide Kurihara

Copyright ( 2018 Yen-Chih Chen et al. This is an open access article distributed under the Creative Commons Attribution License, which permits unrestricted use, distribution, and reproduction in any medium, provided the original work is properly cited.

\begin{abstract}
Purpose. To compare refractive and biometric outcomes in patients with type 1 retinopathy of prematurity (ROP) treated with intravitreal injection of ranibizumab (IVR) versus bevacizumab (IVB), at a corrected age of 3 years. Methods. A retrospective case series compared cycloplegic refractive statuses and biometric statuses in patients who received either IVR or IVB for type 1 ROP, from April 2011 to April 2014. Results. A total of 62 eyes (33 patients) with type 1 ROP were evaluated (26 eyes in 13 IVR patients and 36 eyes in 20 IVB patients). There were no differences in birth statuses including gestational age and birth body weight between the two groups. The prevalence of refractive error greater than $1 \mathrm{D}$ was higher in the IVB group $(p=0.03)$, and there was a higher prevalence of high myopia $(<-5.0 \mathrm{D}, p=0.03)$ in the IVB group. Comparisons in biometric finding showed that IVB patients had shallower anterior chamber depth $(p=0.01)$. Conclusion. Both IVR and IVB showed low refractive errors, even followed at the corrected age of 3 years. No difference was noted between the two groups in refractive statuses. However, IVB was associated with shallower anterior chamber and higher prevalence of refractive error at the corrected age of 3 years. This trial is registered with NCT03334513.
\end{abstract}

\section{Introduction}

Retinopathy of prematurity (ROP) is a neovascular retinal disorder in preterm infants and is one of the major causes of childhood blindness. Although laser photocoagulation had been the main treatment for ROP, the Early Treatment for Retinopathy of Prematurity (ETROP) [1] study and other studies [2-4] have shown that laser photocoagulation results in high prevalence of both myopia and high myopia. Recent studies have reported the use of antivascular endothelial growth factor agents (anti-VEGF) to be effective in the treatment of type 1 ROP [5-7]. As for refractive outcomes, later studies have shown comparatively better refractive outcomes in bevacizumab-treated eyes versus laser-treated eyes $[8,9]$. In addition to bevacizumab, intravitreal injection of ranibizumab (Lucentis; Genentech Inc.) has also been used for ROP treatment [10]. It has been proven that the use of ranibizumab can cause less systemic VEGF suppression as compared to bevacizumab [11]. Up to now, the efficacy of the 2 agents in regressing ROP has continued to be inconsistent. Some authors suggest that ranibizumab leads to a higher ROP relapse rate as compared to bevacizumab [12-14]. On the other hand, Chen et al. [15] have suggested that both agents have good efficacy without ROP regression in their cases. Interestingly, myopia was found to be more prevalent in the bevacizumab treatment group at 1 year follow-up. 
TABle 1: Demographic data of the patients.

\begin{tabular}{|c|c|c|c|c|c|c|c|c|c|c|c|c|}
\hline Sex & Eye & Anti-VEGF & $\begin{array}{c}\text { GA } \\
\text { (weeks) }\end{array}$ & $\begin{array}{l}\text { BW } \\
(\mathrm{g})\end{array}$ & $\begin{array}{c}\text { PMA } \\
\text { (weeks) }\end{array}$ & Zone & Stage & $\begin{array}{l}\text { Plus } \\
\text { disease }\end{array}$ & $\begin{array}{c}\text { Rubeosis } \\
\text { iridis }\end{array}$ & $\begin{array}{c}\text { Corrected } \\
\text { age (months) }\end{array}$ & $\begin{array}{c}\text { CYL } \\
\text { (diopters) }\end{array}$ & $\begin{array}{c}\text { SE } \\
\text { (diopters) }\end{array}$ \\
\hline $\mathrm{F}$ & $\mathrm{OU}$ & $\mathrm{R}$ & 27 & 715 & 37 & $2 / 2$ & $3 / 3$ & $+/+$ & $-1-$ & 32 & $-1.750 /-0.500$ & $-0.125 / 0.000$ \\
\hline M & $\mathrm{OU}$ & $\mathrm{R}$ & 29 & 1402 & 40 & $3 / 3$ & $3 / 3$ & $+/+$ & $-1-$ & 36 & $-0.750 /-1.250$ & $0.125 /-0.625$ \\
\hline M & $\mathrm{OU}$ & $\mathrm{R}$ & 25 & 832 & 34 & $2 / 2$ & $3 / 3$ & $-1-$ & $-1-$ & 35 & $-1.250 /-0.500$ & $-1.375 /-1.250$ \\
\hline M & $\mathrm{OU}$ & $\mathrm{R}$ & 31 & 1350 & 36 & $2 / 2$ & $3 / 3$ & $+/+$ & $-1-$ & 30 & $-2.000 /-1.250$ & $-0.750 /-0.625$ \\
\hline M & $\mathrm{OU}$ & $\mathrm{R}$ & 26 & 1138 & 35 & $22 /$ & $3 / 3$ & $+/+$ & $-1-$ & 36 & $-0.750 /-0.750$ & $0.125 / 0.625$ \\
\hline $\mathrm{F}$ & $\mathrm{OU}$ & $\mathrm{R}$ & 26 & 521 & 39 & $2 / 2$ & $3 / 3$ & $+/+$ & $-1-$ & 37 & $-1.000 /-0.750$ & $1.000 / 0.375$ \\
\hline M & $\mathrm{OU}$ & $\mathrm{R}$ & 28 & 1115 & 39 & $2 / 2$ & $3 / 3$ & $+/+$ & $-1-$ & 31 & $-0.250 /-1.000$ & $0.125 / 0.250$ \\
\hline $\mathrm{F}$ & $\mathrm{OU}$ & $\mathrm{R}$ & 30 & 969 & 36 & $2 / 2$ & $3 / 3$ & $+/+$ & $-1-$ & 35 & $-0.500 /-1.000$ & $-0.500 /-0.250$ \\
\hline $\mathrm{F}$ & $\mathrm{OU}$ & $\mathrm{R}$ & 25 & 758 & 35 & $2 / 2$ & $3 / 3$ & $+/+$ & $-1-$ & 38 & $-1.250 /-2.000$ & $0.875 / 0.250$ \\
\hline $\mathrm{F}$ & $\mathrm{OU}$ & $\mathrm{R}$ & 24 & 537 & 33 & $1 / 1$ & $3 / 3$ & $+/+$ & $-1-$ & 31 & $-0.750 /-1.750$ & $0.375 / 0.125$ \\
\hline $\mathrm{F}$ & $\mathrm{OU}$ & $\mathrm{R}$ & 26 & 507 & 33 & $1 / 1$ & $3 / 3$ & $+/+$ & $+/+$ & 39 & $-0.500 /-1.500$ & $0.500 / 1.000$ \\
\hline $\mathrm{F}$ & $\mathrm{OU}$ & $\mathrm{R}$ & 24 & 554 & 32 & $1 / 1$ & $3 / 3$ & $+/+$ & $-1-$ & 35 & $-3.750 /-3.500$ & $-3.125 /-3.000$ \\
\hline M & $\mathrm{OU}$ & $\mathrm{R}$ & 24 & 732 & 40 & $1 / 2$ & $3 / 3$ & $+/+$ & $-1-$ & 37 & $-0.250 /-0.250$ & $1.625 / 1.125$ \\
\hline M & $\mathrm{OU}$ & B & 24 & 839 & 36 & $2 / 2$ & $3 / 3$ & $+/+$ & $-1-$ & 33 & $-0.750 /-0.750$ & $1.875 / 1.625$ \\
\hline $\mathrm{F}$ & OD & B & 26 & 780 & 33 & 2 & 3 & + & - & 37 & -1.000 & 0.000 \\
\hline $\mathrm{F}$ & $\mathrm{OU}$ & B & 25 & 720 & 36 & $2 / 2$ & $3 / 3$ & $+/+$ & $-1-$ & 34 & $-0.750 /-0.500$ & $2.625 / 2.250$ \\
\hline $\mathrm{M}$ & $\mathrm{OU}$ & B & 27 & 826 & 40 & $2 / 2$ & $3 / 3$ & $+/+$ & $-1-$ & 32 & $-1.500 /-10.250$ & $-0.250 /-0.125$ \\
\hline $\mathrm{F}$ & $\mathrm{OU}$ & B & 24 & 686 & 35 & $2 / 2$ & $3 / 3$ & $+/+$ & $-1-$ & 37 & $-1.250 /-0.750$ & $-0.875 /-7.875$ \\
\hline $\mathrm{M}$ & $\mathrm{OU}$ & B & 30 & 1247 & 35 & $2 / 2$ & $3 / 3$ & $+/+$ & $-1-$ & 35 & $-0.750 /-0.500$ & $0.375 /-0.500$ \\
\hline M & OS & B & 28 & 974 & 46 & 2 & 3 & + & - & 34 & -0.500 & -0.250 \\
\hline $\mathrm{M}$ & $\mathrm{OU}$ & B & 28 & 1039 & 38 & $2 / 2$ & $3 / 3$ & $+/+$ & $-1-$ & 35 & $-1.750 /-1.500$ & $-11.625 /-7.750$ \\
\hline M & $\mathrm{OU}$ & B & 24 & 729 & 39 & $2 / 2$ & $3 / 3$ & $+/+$ & $-1-$ & 36 & $-2.000 /-2.000$ & $2.000 / 4.250$ \\
\hline $\mathrm{F}$ & $\mathrm{OU}$ & B & 26 & 724 & 35 & $2 / 2$ & $3 / 3$ & $+/+$ & $+/+$ & 36 & $-0.750 /-0.750$ & $2.125 / 2.375$ \\
\hline $\mathrm{F}$ & $\mathrm{OU}$ & B & 28 & 1060 & 36 & $2 / 2$ & $3 / 2$ & $+/+$ & $-1-$ & 38 & $-2.750 /-1.500$ & $-0.375 / 0.500$ \\
\hline $\mathrm{F}$ & OD & B & 27 & 954 & 42 & 2 & 3 & + & - & 37 & -1.000 & 2.000 \\
\hline $\mathrm{F}$ & $\mathrm{OU}$ & B & 25 & 751 & 35 & $2 / 2$ & $2 / 2$ & $+/+$ & $-1-$ & 34 & $-0.750 /-0.500$ & $0.125 / 0.250$ \\
\hline $\mathrm{F}$ & OD & B & 25 & 569 & 38 & 2 & 3 & + & - & 37 & -1.750 & 0.375 \\
\hline $\mathrm{F}$ & $\mathrm{OU}$ & B & 26 & 910 & 37 & $2 / 2$ & $3 / 3$ & $+/+$ & $-1-$ & 35 & $-2.500 /-3.000$ & $1.000 / 1.250$ \\
\hline M & $\mathrm{OU}$ & B & 28 & 1003 & 40 & $2 / 2$ & $3 / 3$ & $+/+$ & $-1-$ & 37 & $-0.500 /-0.500$ & $1.000 / 1.000$ \\
\hline M & $\mathrm{OU}$ & B & 32 & 1150 & 43 & $2 / 2$ & $3 / 3$ & $+/+$ & $-1-$ & 32 & $0.000 / 0.000$ & $1.250 / 1.250$ \\
\hline $\mathrm{F}$ & $\mathrm{OU}$ & B & 32 & 1023 & 36 & $2 / 2$ & $3 / 3$ & $+/+$ & $-1-$ & 32 & $0.000 /-1.250$ & $0.750 / 0.375$ \\
\hline $\mathrm{F}$ & $\mathrm{OU}$ & B & 28 & 1120 & 32 & $2 / 2$ & $3 / 3$ & $+/+$ & $-1-$ & 39 & $-3.500 /-3.250$ & $-5.250 /-12.125$ \\
\hline $\mathrm{M}$ & $\mathrm{OU}$ & B & 27 & 934 & 35 & $2 / 2$ & $3 / 3$ & $+/+$ & $-1-$ & 35 & $-3.750 /-3.000$ & $-5.375 /-1.500$ \\
\hline
\end{tabular}

B: bevacizumab; BW: birth weight; CYL: cylinder; F: female; GA: gestational age; M: male; OD: right eye; OS: left eye; OU: both eyes; PMA: postmenstrual age; R: ranibizumab; SE: spherical equivalent.

However, the results were only followed until the corrected age of 1 year. The long-term differences between the two medications in regard to the development of refractive errors have remained unknown. In addition, concerning refractive errors in ROP children, it is reported that the development of refractive errors is mainly influenced by anterior segment abnormalities such as steep corneal curvature, shallow anterior chamber depth or a relatively thick lens, rather than long axial length [16, 17]. But research into the differences in optic components between children receiving the two anti-VEGF agents has not yet been conducted. In this study, we aimed to investigate refractive outcomes over a longer follow-up at the corrected age of 3 years and compare effects on optical components of ROP patients between the two medications.

\section{Materials and Methods}

This is a retrospective study of type 1 ROP infants treated with IVI of anti-VEGF agents, in Changhua Christian Hospital, Changhua, Taiwan, from April 2011 to April 2014. The study was approved by the Institutional Review Board of the hospital and adhered to the Declaration of Helsinki. Only infants who received intravitreal injection of ranibizumab (IVR) or bevacizumab (IVB) as the primary treatment for ROP were included. Infants who received laser treatment 
TABLE 2: Comparison of demographic data between patients treated with ranibizumab or bevacizumab.

\begin{tabular}{|c|c|c|c|c|c|}
\hline & \multicolumn{2}{|c|}{ Ranibizumab $(N=26)$} & \multicolumn{2}{|c|}{ Bevacizumab $(N=36)$} & \multirow{2}{*}{$p^{*}$} \\
\hline & Mean \pm SD & Median (95\% CI) & Mean \pm SD & Median (95\% CI) & \\
\hline GA (weeks) & $26.54 \pm 2.28$ & $26.00(25.00$ to 27.45$)$ & $27.06 \pm 2.43$ & $27.00(26.00$ to 28.0$)$ & 0.38 \\
\hline $\mathrm{BW}(\mathrm{g})$ & $856.15 \pm 306.46$ & $758.00(642.36$ to 1034.87$)$ & $911.08 \pm 175.17$ & 922.00 (810.31 to 1009.82$)$ & 0.23 \\
\hline PMA at IVI (weeks) & $36.12 \pm 2.72$ & $36.00(34.55$ to 38.45$)$ & $37.19 \pm 3.28$ & $36.00(35.00$ to 38.00$)$ & 0.26 \\
\hline Corrected age (months) & $34.77 \pm 2.83$ & $35.00(33.65$ to 36.45$)$ & $35.08 \pm 1.97$ & $35.00(34.00$ to 36.00$)$ & 0.80 \\
\hline
\end{tabular}

BW: birth weight; GA: gestational age; PMA: postmenstrual age; * Mann-Whitney $U$ test.

whether as primary or as salvage treatment were excluded. Informed consent was obtained from the parents for the surgical procedures. The treatment indications were type 1 ROP disease, which was defined as zone I ROP with plus disease, zone I stage III ROP, and zone II stages 2-3 with plus disease according to the report of ETROP. The parents were well informed about the treatment choices, including laser treatment, or intravitreal injection of anti-VEGF agents. The efficacy and possible complications of each treatment were well explained. In addition, the difference between two anti-VEGF agents (ranibizumab or bevacizumab), such as different systemic VEGF suppression and differences in self-paid costs, were also well explained.

Medical records were collected in each treatment group for birth history data, including gestational age (GA), birth weight (BW), and postmenstrual age (PMA) at IVI. The zone and stage of ROP and corrected age at each visit were also recorded. All patients were evaluated routinely for refractive errors and optical components at the age of 1,2 , and 3 years. Cycloplegic refraction was performed at each visit, using a desktop computer auto kerato-refractometer (Topcon KR-8100, Tokyo, Japan), and was confirmed by retinoscopy examination. Refractive errors were calculated as spherical equivalent (SE) and astigmatism in cylinder. The average corneal radius (CR) was also measured (Topcon KR-8100, Tokyo, Japan). The biometric optic components, including anterior chamber depth (ACD), lens thickness (LT), and axial length (AL), were measured with an A-scan ultrasound (model A-1500; Sonomed, Lake Success, NY, USA). Refractive error was defined as follows: high myopia $(\mathrm{SE} \leq-5 \mathrm{D})$, low myopia (SE $>-5 \mathrm{D}$ to $-1 \mathrm{D})$, emmetropia ( $\mathrm{SE}>-1 \mathrm{D}$ to $+1 \mathrm{D})$, low hyperopia (SE $>+1 \mathrm{D}$ to $+4 \mathrm{D})$, and high hyperopia $(\mathrm{SE}>+4 \mathrm{D})$.

2.1. Surgical Technique and Follow-Up. The technique for IVI of anti-VEGF agents was as previous stated [13]. After topical anesthesia, the eyes were draped and disinfected with 5\% povidone-iodine and topical antibiotic use. Either $0.625 \mathrm{mg}$ $(0.025 \mathrm{~mL})$ of bevacizumab or $0.25 \mathrm{mg}(0.025 \mathrm{~mL})$ of ranibizumab was injected intravitreally $1.5 \mathrm{~mm}$ posterior to the limbus. After injection, intraocular pressure and retinal artery perfusion were checked and patients received topical antibiotics for 7 days. All patients were followed every 1 or 2 weeks following injection, until regression of ROP was observed. Then patients were scheduled for regular outpatient follow-up until at least a corrected age of 3 years. Indirect fundoscopy was performed to examine the retina and vascularization during each visit. The patients with poor
TABLE 3: Disease status of ROP patients, by ranibizumab or bevacizumab treatment.

\begin{tabular}{lccc}
\hline & Ranibizumab $(N=26)$ & Bevacizumab $(N=36)$ & $p^{*}$ \\
\hline Zone, $N(\%)$ & & & 0.02 \\
I & $7(27 \%)$ & $2(6 \%)$ & \\
II & $19(73 \%)$ & $34(94 \%)$ & \\
Stage, $N(\%)$ & & & \\
2 & $0(0 \%)$ & $3(8 \%)$ & 0.25 \\
3 & $26(100 \%)$ & $33(92 \%)$ & \\
\hline
\end{tabular}

*Fisher's exact test.

response to anti-VEGF treatment or progression in ROP severity subsequently received laser treatment.

2.2. Statistical Analysis. Statistical analysis was performed using MedCalc software version 16.8.4 (MedCalc Software, Mariakerke, Belgium). Numerical data is expressed as mean \pm standard deviation and median with $95 \%$ confidence interval. We used the Mann-Whitney $U$ test to compare differences in baseline data (GA, BW, PAM at IVI, corrected age during follow-up), refractive status (SE, cylinder), and biometric components ( $\mathrm{AL}$, mean cornea radius, $\mathrm{ACD}, \mathrm{LT}$ ) between the two treatment groups. Fisher's exact test was conducted to compare differences regarding the ROP zones, stages, and presence of plus disease between the two treatment groups. It was also used to test the differences in the prevalence of refractive error between the two treatment groups. A $p$ value $<0.05$ was considered to be statistically significant.

\section{Results}

Table 1 listed the demographic data of our ROP patients. A total of 36 ROP patients were reviewed. Among these patients, 4 eyes from 3 patients in the IVB group had received photocoagulation treatment 2-3 weeks after the IVI of bevacizumab, due to failure of regression of retinal neovascularization, and were excluded from the study. Therefore, a total of 62 eyes in 33 patients ( 15 males and 18 females) were included in the study.

26 eyes from 13 patients belonged to the IVR group, and 36 eyes from 20 patients belonged to the IVB group. Among these patients, 9 of 62 eyes had zone I ROP, and 53 of 62 eyes had zone II ROP; 3 of 62 eyes had stage 2 ROP, and 59 of 62 eyes had stage 3 ROP. There were no differences in GA, BBW, or PMA at IVI, and corrected 


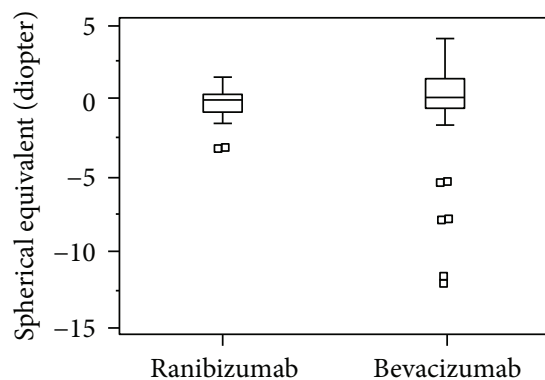

(a)

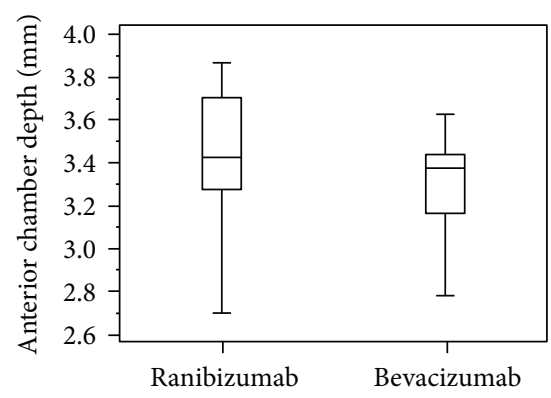

(d)

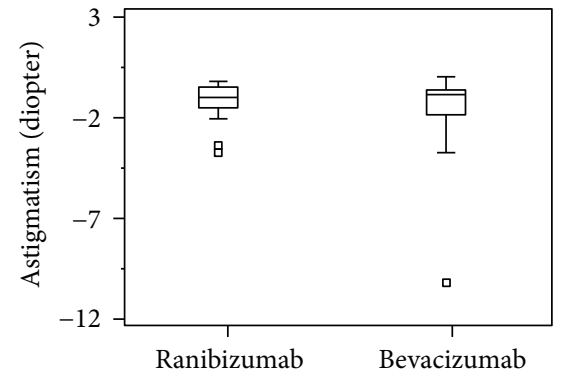

(b)

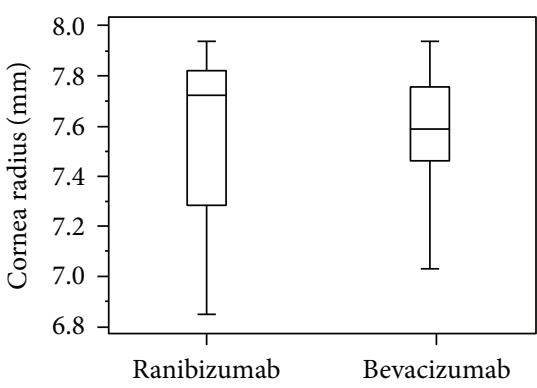

(e)

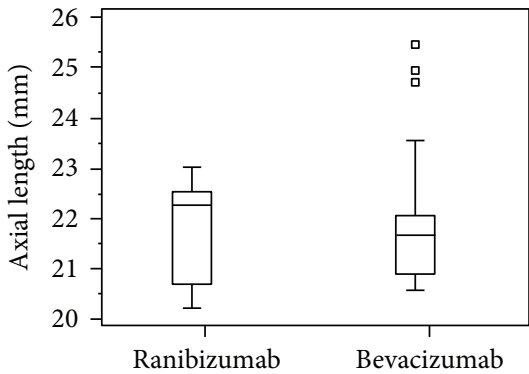

(c)

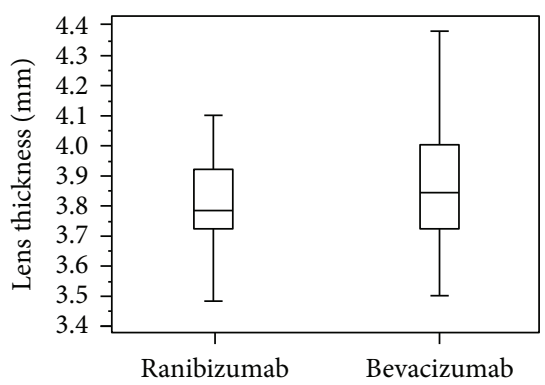

(f)

FIGURE 1: Box plots showing the distribution of refractive status and biometric comparisons at the corrected age of 3 years in children with ROP, treated with IVIs of either ranibizumab or bevacizumab. (a) Spherical equivalent; (b) astigmatism; (c) axial length; (d) anterior chamber depth; (e) cornea radius; (f) lens thickness. There was a significant difference only in anterior chamber depth $(p=0.01)$ between the eyes in the two groups but the differences were not seen in other parameters.

TABLE 4: Refractive errors and biometry in patients treated with ranibizumab or bevacizumab.

\begin{tabular}{|c|c|c|c|c|c|}
\hline & \multicolumn{2}{|c|}{ Ranibizumab $(N=26)$} & \multicolumn{2}{|c|}{ Bevacizumab $(N=36)$} & \multirow[b]{2}{*}{$p^{*}$} \\
\hline & Mean \pm SD & Median (95\% CI) & Mean \pm SD & Median (95\% CI) & \\
\hline SE (diopters) & $-0.12 \pm 1.12$ & $+0.13(-0.36$ to +0.38$)$ & $-0.65 \pm 3.83$ & $+0.38(-0.17$ to +1.09$)$ & 0.19 \\
\hline Cylinder (diopters) & $-1.18 \pm 0.89$ & $-1.00(-1.30$ to -0.75$)$ & $-1.60 \pm 1.80$ & $-1.00(-1.59$ to -0.75$)$ & 0.55 \\
\hline Axial length (mm) & $21.90 \pm 0.94$ & 22.33 (21.39 to 22.56$)$ & $21.90 \pm 1.27$ & 21.67 (21.31 to 21.95$)$ & 0.22 \\
\hline Cornea radius (mm) & $7.64 \pm 0.26$ & $7.76(7.45$ to 7.83$)$ & $7.60 \pm 0.22$ & $7.60(7.52$ to 7.68$)$ & 0.35 \\
\hline $\mathrm{ACD}(\mathrm{mm})$ & $3.53 \pm 0.22$ & $3.51(3.35$ to 3.74$)$ & $3.33 \pm 0.23$ & $3.37(3.22$ to 3.44$)$ & 0.01 \\
\hline Lens thickness $(\mathrm{mm})$ & $3.82 \pm 0.15$ & $3.78(3.74$ to 3.98$)$ & $3.85 \pm 0.20$ & $3.82(3.78$ to 3.94$)$ & 0.60 \\
\hline
\end{tabular}

ACD: anterior chamber depth; SE: spherical equivalent; ${ }^{*}$ Mann-Whitney $U$ test.

age at refraction and biometry was noted between the two groups (Table 2).

There were also no differences in the stage of disease or presence of plus disease or rubeosis iridis between the groups; however, eyes in the IVR group had a higher proportion of zone 1 disease $(p=0.02)$ (Table 3 ).

All studied eyes in both groups during subsequent follow-up showed complete regression of neovascularization, without recurrence. There were no major complications, such as traumatic cataract, retinal detachment, or endophthalmitis, found in the treated eyes.

The distributions of SE, astigmatism, and biometric findings at the corrected age of 3 years in the ROP patients treated with either ranibizumab or bevacizumab are shown in Figure 1. Table 4 gives a comparison in refractive errors and biometric findings between the two treatment groups.

The Mann-Whitney $U$ test showed no significant differences in SE $(-0.12 \pm 1.12 \mathrm{D}$ in the IVR group versus $-0.65 \pm$
3.83 $\mathrm{D}$ in the IVB group, $p=0.19)$ or in cylinder power $(-1.18 \pm 0.89 \mathrm{D}$ in the IVR group versus $-1.60 \pm 1.80 \mathrm{D}$ in the IVB group, $p=0.55)$. Regarding the biometric studies, there was significantly shallower ACD in the IVB group $(3.53 \pm 0.22 \mathrm{~mm}$ in the IVR group versus $3.33 \pm 0.23$ in the IVB group, $p=0.01)$. There were no significant differences in cornea radius, LT, and AL between the two groups.

For the proportion of refractive errors in each group, patients in the IVB group had statistically significant higher proportion of high myopia and hyperopia $(p=0.03)$. Overall, IVB patients had a statistically higher proportion of refractive error greater than $1 \mathrm{D}(p=0.03)$ (Table 5).

\section{Discussion}

In this study, we followed the ROP patients for 3 years after the intravitreal injection of anti-VEGF agents. The results revealed that intravitreal injection of either bevacizumab or 
TABLE 5: Presence of refractive errors of the ROP patients treated with ranibizumab or bevacizumab at the corrected age of 3 years.

\begin{tabular}{lccc}
\hline & Ranibizumab $(N=26)$ & Bevacizumab $(N=36)$ & $p^{*}$ \\
\hline High myopia ( $\leq-5 \mathrm{D})$ & $0(0 \%)$ & $6(16.7 \%)$ & 0.03 \\
Myopia (high + low) ( $\leq-1 \mathrm{D})$ & $4(15.4 \%)$ & $7(19.4 \%)$ & 0.75 \\
High hyperopia (>+4 D) & $0(0 \%)$ & $1(2.8 \%)$ & 1.00 \\
Hyperopia (high + low) $(>+1 \mathrm{D})$ & $2(7.7 \%)$ & $12(33.3 \%)$ & 0.03 \\
Presence of ametropia $(>+1 \mathrm{D}$ or $<-1 \mathrm{D})$ & $6(23.1 \%)$ & $19(52.8 \%)$ & 0.03 \\
\hline
\end{tabular}

*Fisher's exact test.

ranibizumab had good efficacy in the regression of ROP, up to a period of 3 years of age. Different from other previous studies, which showed that intravitreal injection of ranibizumab is related with higher incidence of ROP recurrence than bevacizumab $[13,14]$, our study showed that 4 eyes of 3 patients in the IVB group needed photocoagulation therapy for nonresponse, while no patients in the IVR group needed further therapy. In the comparison of refractive outcomes and biometric parameters in the two treatment groups, we found no differences regarding SE or astigmatism between the two groups at the corrected age of 3 years. However, a higher proportion of refractive error was found in patients of the IVB group as compared with patients in the IVR group. In our previous study [15], patients in the IVB group had a significantly higher incidence of high myopia (14.6\% IVB versus $0.0 \%$ IVR) at the corrected age of 1 year. In this study, the higher incidence of high myopia was still noted at 3 years of corrected age ( $16.7 \%$ IVB versus $0.0 \%$ IVR). In addition, we noted a statically higher incidence of hyperopia in the IVB group and a higher incidence of refractive error greater than $1 \mathrm{D}$ in the IVB group ( $p=0.03$ and 0.03 , resp.). A higher chance of ametropia, including hyperopia, has also been reported in previous reports on ROP children [16, 17]. The possible mechanism may be related to the longer halflife of bevacizumab; this may increase the apoptosis of peripheral retinal structures, which are responsible for the normal emmetropization process [18]. This is because inhibition of VEGF receptors has been found to lead to a loss of Müller cells, astrocytes, and ganglion cells from the inner retina in an animal study [19]. However, the effect in human eyes remains unclear. Previous studies [20-22] have shown that anterior segment abnormalities (including a steeper cornea, shallower anterior chamber, and greater lens thickness, rather than axial length elongation) were the factors contributing to refractive errors in ROP children given laser treatment. In our study, we found that children in both groups had similar cornea curvature, lens thickness, and axial length. However, a shallower anterior chamber depth in the IVB group was found. This may partially explain the higher incidence of high myopia noted in the IVB group. Previous studies have shown that the arrested development of the anterior chamber may contribute to the development of myopia [23]. As compared to ranibizumab, the prolonged suppression of VEGF by bevacizumab may have a greater impact on the development of the anterior chamber; however, the mechanism needs to be further clarified in future studies.

\section{Conclusion}

In conclusion, we followed type 1 ROP patients who have received intravitreal injection of bevacizumab or ranibizumab as the main treatment, until a correction of 3 years. The results revealed good efficacy in ROP regression with both medications. The mean refractive error is similar between the two treatments, while patients receiving bevacizumab had shallower anterior chamber and higher incidence of ametropia. The difference in the duration of VEGF suppression may be responsible for the different incidence of ametropia and differences in anterior chamber depth between the two groups. The limitations of this study include the small sample size and the retrospective nature. Future studies with larger sample sizes and a prospective nature are needed to further confirm the results.

\section{Ethical Approval}

This retrospective chart review study was approved by IRB review.

\section{Disclosure}

It should be noted that this article does not contain any personal medical information about an identifiable living individual.

\section{Conflicts of Interest}

The authors declare that there is no conflict of interest regarding the publication of this article.

\section{References}

[1] W. V. Good and Early treatment for retinopathy of prematurity cooperative group, "Final results of the Early Treatment for Retinopathy of Prematurity (ETROP) randomized trial," Transactions of the American Ophthalmological Society, vol. 102, pp. 233-248, 2004.

[2] R. Axer-Siegel, I. Maharshak, M. Snir et al., "Diode laser treatment of retinopathy of prematurity: anatomical and refractive outcomes," Retina, vol. 28, no. 6, pp. 839-846, 2008.

[3] A. Dhawan, M. Dogra, A. Vinekar, A. Gupta, and S. Dutta, "Structural sequelae and refractive outcome after successful laser treatment for threshold retinopathy of prematurity," Journal of Pediatric Ophthalmology and Strabismus, vol. 45, no. 6, pp. 356-361, 2008. 
[4] J. Sahni, N. V. Subhedar, and D. Clark, "Treated threshold stage 3 versus spontaneously regressed subthreshold stage 3 retinopathy of prematurity: a study of motility, refractive, and anatomical outcomes at 6 months and 36 months," The British Journal of Ophthalmology, vol. 89, no. 2, pp. 154159, 2005.

[5] H. A. Mintz-Hittner, K. A. Kennedy, A. Z. Chuang, and BEAT-ROP Cooperative Group, "Efficacy of intravitreal bevacizumab for stage $3+$ retinopathy of prematurity," The New England Journal of Medicine, vol. 364, no. 7, pp. 603615, 2011.

[6] W. C. Wu, P. T. Yeh, S. N. Chen, C. M. Yang, C. C. Lai, and H. K. Kuo, "Effects and complications of bevacizumab use in patients with retinopathy of prematurity: a multicenter study in Taiwan," Ophthalmology, vol. 118, no. 1, pp. 176-183, 2011.

[7] W. C. Wu, H. K. Kuo, P. T. Yeh, C. M. Yang, C. C. Lai, and S. N. Chen, "An updated study of the use of bevacizumab in the treatment of patients with prethreshold retinopathy of prematurity in Taiwan," American Journal of Ophthalmology, vol. 155, no. 1, pp. 150-158.e1, 2013.

[8] B. C. Harder, F. C. Schlichtenbrede, S. von Baltz, W. Jendritza, B. Jendritza, and J. B. Jonas, "Intravitreal bevacizumab for retinopathy of prematurity: refractive error results," American Journal of Ophthalmology, vol. 155, no. 6, pp. 11191124.e1, 2013.

[9] C. K. Hwang, G. B. Hubbard, A. K. Hutchinson, and S. R. Lambert, "Outcomes after intravitreal bevacizumab versus laser photocoagulation for retinopathy of prematurity: a 5-year retrospective analysis," Ophthalmology, vol. 122, no. 5, pp. 1008-1015, 2015.

[10] G. Zhang, M. Yang, J. Zeng et al., "Comparison of intravitreal injection of ranibizumab versus laser therapy for zone II treatment-requiring retinopathy of prematurity," Retina, vol. 37, no. 4, pp. 710-717, 2017.

[11] W. C. Wu, C. P. Shih, R. Lien et al., "Serum vascular endothelial growth factor after bevacizumab or ranibizumab treatment for retinopathy of prematurity," Retina, vol. 37, no. 4, pp. 694$701,2017$.

[12] J. J. T. Chan, C. P. S. Lam, M. K. M. Kwok et al., "Risk of recurrence of retinopathy of prematurity after initial intravitreal ranibizumab therapy," Scientific Reports, vol. 6, no. 1, article 27082, 2016.

[13] T. Chuluunbat, R. V. Paul Chan, N.-K. Wang et al., "Nonresponse and recurrence of retinopathy of prematurity after intravitreal ranibizumab treatment," Ophthalmic Surgery, Lasers and Imaging Retina, vol. 47, no. 12, pp. 10951105, 2016.

[14] M. K. Erol, D. T. Coban, E. S. Sari et al., "Comparison of intravitreal ranibizumab and bevacizumab treatment for retinopathy of prematurity," Arquivos Brasileiros de Oftalmologia, vol. 78, no. 6, pp. 340-343, 2015.

[15] S. N. Chen, I. Lian, Y. C. Hwang et al., "Intravitreal antivascular endothelial growth factor treatment for retinopathy of prematurity: comparison between ranibizumab and bevacizumab," Retina, vol. 35, no. 4, pp. 667-674, 2015.

[16] T. C. Chen, T. H. Tsai, Y. F. Shih et al., "Long-term evaluation of refractive status and optical components in eyes of children born prematurely," Investigative Ophthalmology \& Visual Science, vol. 51, no. 12, p. 6140, 2010.

[17] W. C. Wu, R. I. Lin, C. P. Shih et al., "Visual acuity, optical components, and macular abnormalities in patients with a history of retinopathy of prematurity," Ophthalmology, vol. 119, no. 9, pp. 1907-1916, 2012.

[18] E. L. Smith III, "Prentice Award Lecture 2010: a case for peripheral optical treatment strategies for myopia," Optometry and Vision Science, vol. 88, no. 9, pp. 1029-1044, 2011.

[19] G. S. Robinson, M. Ju, S. C. Shih et al., "Nonvascular role for VEGF: VEGFR-1, 2 activity is critical for neural retinal development," The FASEB Journal, vol. 15, no. 7, pp. 12151217, 2001.

[20] J. Wang, X. Ren, L. Shen, S. E. Yanni, J. N. Leffler, and E. E. Birch, "Development of refractive error in individual children with regressed retinopathy of prematurity," Investigative Opthalmology \& Visual Science, vol. 54, no. 9, pp. 60186024, 2013.

[21] C. S. Yang, A. G. Wang, Y. F. Shih, and W. M. Hsu, "Longterm biometric optic components of diode laser-treated threshold retinopathy of prematurity at 9 years of age," Acta Ophthalmologica, vol. 91, no. 4, pp. e276-e282, 2013.

[22] B. P. Connolly, E. Y. J. Ng, J. Arch McNamara, C. D. Regillo, J. F. Vander, and W. Tasman, "A comparison of laser photocoagulation with cryotherapy for threshold retinopathy of prematurity at 10 years," Ophthalmology, vol. 109, no. 5, pp. 936-941, 2002.

[23] A. R. Fielder and G. E. Quinn, "Myopia of prematurity: nature, nurture, or disease?," The British Journal of Ophthalmology, vol. 81, no. 1, pp. 2-3, 1997. 


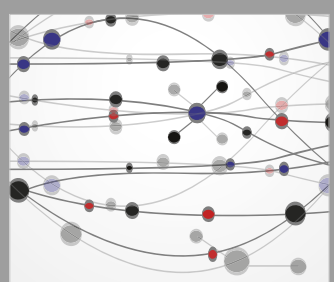

The Scientific World Journal
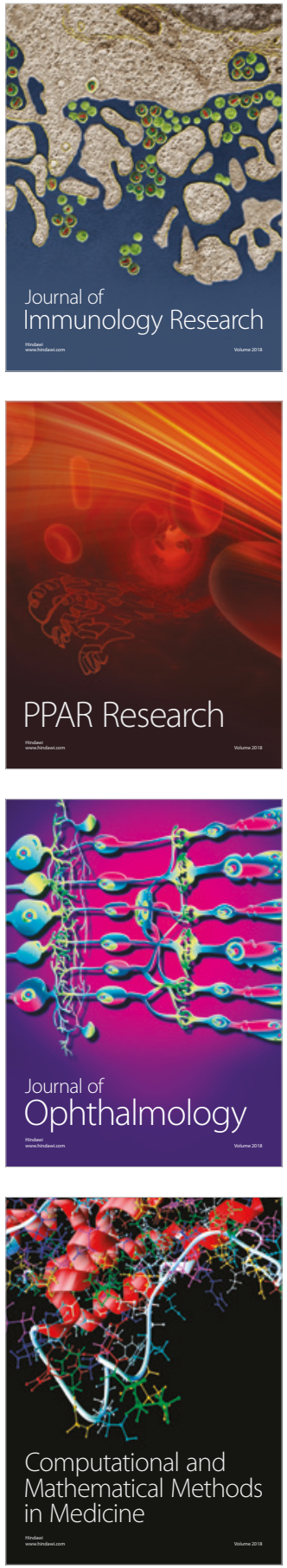

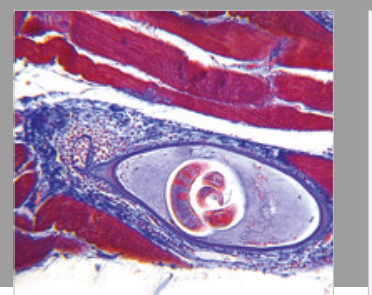

Gastroenterology Research and Practice

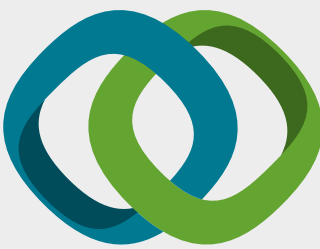

\section{Hindawi}

Submit your manuscripts at

www.hindawi.com
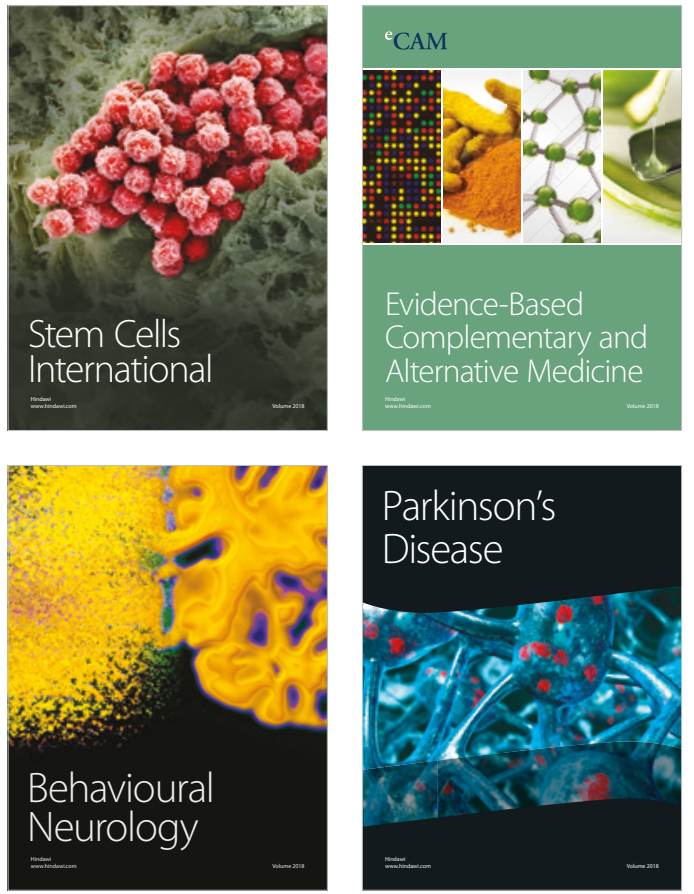

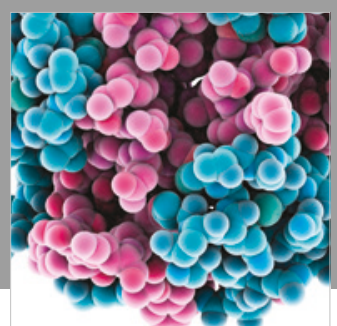

ournal of

Diabetes Research

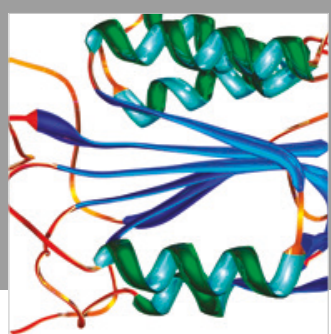

Disease Markers
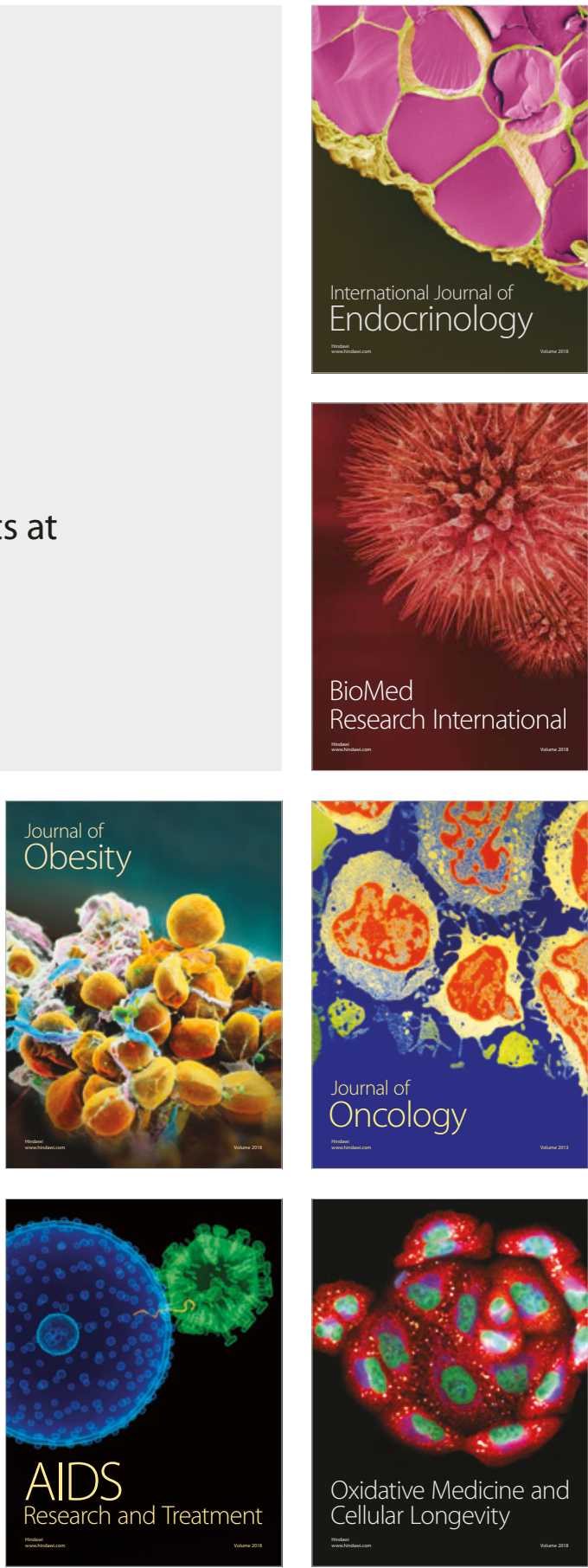